\title{
The Forkhead transcription factor Hcm 1 regulates chromosome segregation genes and fills the S-phase gap in the transcriptional circuitry of the cell cycle
}

\author{
Tata Pramila, ${ }^{1}$ Wei Wu, ${ }^{1,2,3}$ Shawna Miles, ${ }^{1}$ William Stafford Noble, ${ }^{2,5}$ and Linda L. Breeden ${ }^{1,4}$ \\ ${ }^{1}$ Fred Hutchinson Cancer Research Center, Seattle, Washington 98109, USA; ${ }^{2}$ Department of Genome Sciences, University \\ of Washington, Seattle, Washington 98195, USA
}

Transcription patterns shift dramatically as cells transit from one phase of the cell cycle to another. To better define this transcriptional circuitry, we collected new microarray data across the cell cycle of budding yeast. The combined analysis of these data with three other cell cycle data sets identifies hundreds of new highly periodic transcripts and provides a weighted average peak time for each transcript. Using these data and phylogenetic comparisons of promoter sequences, we have identified a late S-phase-specific promoter element. This element is the binding site for the forkhead protein $\mathrm{Hcm} 1$, which is required for its cell cycle-specific activity. Among the cell cycle-regulated genes that contain conserved Hcm1-binding sites, there is a significant enrichment of genes involved in chromosome segregation, spindle dynamics, and budding. This may explain why Hcm1 mutants show 10-fold elevated rates of chromosome loss and require the spindle checkpoint for viability. $H \mathrm{~cm} 1$ also induces the M-phase-specific transcription factors FKH1, FKH2, and NDD1, and two cell cycle-specific transcriptional repressors, WHI5 and YHP1. As such, Hcm1 fills a significant gap in our understanding of the transcriptional circuitry that underlies the cell cycle.

[Keywords: Hcm1; cell cycle; transcription; genome stability; forkhead; yeast]

Supplemental material is available at http://www.genesdev.org.

Received May 18, 2006; revised version accepted June 21, 2006.

About $15 \%$ of budding yeast genes are subject to transcriptional regulation during the cell cycle. This large outlay of regulatory effort persists in bacteria as well as metazoans, where the types of transcription factors (TFs) involved and their targets show significant conservation (Alvarez et al. 2001; Costa 2005). Rapid elimination of cell cycle regulators typically involves protein degradation, sequestration, or modification (Vodermaier 2004). However, transcriptional regulation controls an equally important step, which is when these cell cycle-specific regulators are first expressed.

Genome-wide transcript measurements for the budding yeast cell cycle were among the first microarray experiments carried out (Cho et al. 1998; Spellman et al. 1998). Many computational methods have been used to

\footnotetext{
${ }^{3}$ Present address: Microsoft Corp., One Microsoft Way, Redmond, WA 98052, USA.

Corresponding authors.

${ }^{4}$ E-MAIL lbreeden@fhcrc.org; FAX (206) 667-6526.

${ }^{5}$ E-MAIL noble@gs.washington.edu; FAX (206) 685-7301.

Article is online at http://www.genesdev.org/cgi/doi/10.1101/gad.1450606.
}

identify cell cycle-regulated transcripts from these data, but there remains a remarkable level of uncertainty. Nearly one-third of the budding yeast genes have been classified as periodic by at least one method, yet $<200$ genes have been classified as periodic by all methods (de Lichtenberg et al. 2005b; data not shown). This ambiguity stems from noise in the data, lack of replicates within a given time course, and variation imposed by the different synchrony methods used. In spite of these obstacles, these data have been the subject of scores of computational and experimental strategies aimed at understanding the regulatory circuitry of the cell cycle.

One outcome of this global scrutiny of transcription through the cell cycle is the realization that gene products that are required at a specific point in the cycle are very often periodically transcribed, and peak at a time appropriate for their function (de Lichtenberg et al. 2005a). The TFs provide a particularly dramatic example of this phenomenon (Simon et al. 2001). Of the 13 TFs known to be involved in cell cycle-specific transcription, all but three are periodically transcribed and peak just 
before they are needed. This "just in time" expression may reinforce the order of events, but it may also be important for replenishing pools of gene products that are inactivated after they perform their function or during prolonged arrests (e.g., quiescence or stationary phase). Periodic transcription of an unstable regulator can also serve as a rate-limiting step in the cycle. Swi4 is a dose-dependent activator of the transition from G1 to $S$ phase, and if its transcription is shifted from early to late G1, there is a corresponding delay in the transition to S phase (McInerny et al. 1997). The extent to which cell cycle-regulated transcription contributes to the orderly duplication of a cell has not yet been thoroughly explored. However, results to date suggest that a comprehensive description of the scope and timing of transcription through the cell cycle would provide insight into most, if not all, cell cycle-specific processes and would identify many of the TFs that underlie that regulation.

G1 is the key control point during which the decision is made to commit to another round of division in most organisms. One of the first insights into this process in budding yeast was the discovery of a cyclin $\mathrm{Cln} 3$, whose overexpression speeds the G1-to-S transition (Cross 1988; Nash et al. 1988). The expression of this first cyclin activates the transcription of a battery of late G1 genes including cyclins and many genes involved in DNA replication and budding (Tyers et al. 1993; Dirick et al. 1995; Stuart and Wittenberg 1996; MacKay et al. 2001). Late G1 transcription is carried out by two DNAbinding proteins (Swi4 or Mbp1), which are structurally related and associate with a common subunit called Swi6. These proteins are bound to late G1 promoters throughout G1 (Cosma et al. 1999) in an inactive state due to the presence of an inhibitor Whi5 (Costanzo et al. 2004; de Bruin et al. 2004). Cln3 complexed with the cyclin-dependent kinase (Cdk) phosphorylates Whi5, which facilitates its dissociation from these promoters, and late G1-specific transcription ensues. Among the late G1 transcripts is one encoding another repressor, called Yox1, which forms a negative feedback loop by repressing the transcription of CLN3 and SWI4 and other transcripts that peak at the M/G1 border (Pramila et al. 2002).

Little is known about the mechanisms that regulate transcription from early $S$ phase to mitosis. However, M-phase-specific transcription was the first to be understood at the molecular level. Two of the four yeast forkhead TFs act at this interval, along with Mcml and $\mathrm{Ndd1}$, to induce the expression of the last wave of cyclins ( $\mathrm{Clb} 1$ and $\mathrm{Clb} 2)$ and the next wave of transcription factors: Swi5 and Ace2 (Koranda et al. 2000; Kumar et al. 2000; Pic et al. 2000; Zhu et al. 2000). Swi5 and Ace2 then activate genes involved in cell separation (Knapp et al. 1996; Kovacech et al. 1996) and in distinguishing mother cells from daughter cells (Doolin et al. 2001). At about the same time, Mcml is released from repression by a pair of repressors (Yox1 and Yhp1) at another set of $\mathrm{M} / \mathrm{G} 1$-specific promoters, which induce the transcription of genes required to set up prereplication complexes for DNA synthesis (Mcm2-7 and Cdc6) and to restart the cell cycle (Cln3 and Swi4) (Pramila et al. 2002).

In the present study, we fill a critical gap in the transcriptional circuitry of the cell cycle with the discovery of a novel S-phase-specific TF, Hcm 1 . We first generated new microarray data across the budding yeast cell cycle, and carried out combined analysis of these data with three previously collected data sets. This analysis has enabled us to identify hundreds of new cell cycle-regulated transcripts and to calculate a weighted average time at which each transcript peaks. We then searched for phylogenetically conserved elements that were overrepresented within S-phase-specific promoters. This strategy led to the discovery that Hcml, another forkhead TF, is a cell cycle-specific TF that activates transcription during $S$ phase. Consistent with the patterns observed across other phases of the cell cycle, HCM1 is periodically transcribed and expressed in late G1 and early S phase. Hcml's targets peak primarily during late $S$ phase and show a striking enrichment for gene products involved in chromosome organization, spindle dynamics, and budding. Hcm 1 also plays a prominent role in the transcriptional circuitry that underlies the cell cycle in that it is required for the of transcription of $M$ phase TFs: Fkh1, Fkh2, and Ndd1. It is also required for the periodic transcription of the two cell cycle-specific repressors Whi5 and Yhp1.

\section{Results}

\section{Refining the list of periodic transcripts}

We have generated two microarray data sets that follow transcript levels at 5-min intervals over two cell cycles after $\alpha$-factor synchronization. These nearly double the available data, and when combined with three other data sets they offer a more comprehensive look at the periodically transcribed genes of budding yeast. The periodic normal mixture (PNM) method (Lu et al. 2004) was applied to different combinations of data sets to calculate the probability that each gene is periodically transcribed. Using a list of 127 known periodic genes to judge the performance, we found that integrating all five data sets in the analysis (PNM5) performed the best (Supplementary Fig. 1A,B). A total of 1031 genes rank above the probability threshold of 0.95 , and 657 exceed a threshold of 0.9986. Among the latter 657 transcripts, one-quarter were not previously characterized as periodic (Spellman et al. 1998).

A permutation based statistical method (PBM5) was also used to rank periodic transcripts in all five data sets (de Lichtenberg et al. 2005b). PBM ranks each transcript by a score that combines two permutation-based statistical tests for periodicity and magnitude of oscillation. Direct comparison of PNM5 and PBM5 indicates that PBM5 improves the rate of identification of the 127 known periodic transcripts (Supplementary Fig. 2). The top 1000 periodic transcripts calculated by PBM5 have been used for further analysis. An important feature of PBM5 is that a weighted average peak time is calculated 
for each periodic transcript (de Lichtenberg et al. 2005b). These results, including the rank order and peak times, are available at our Web site (http://www.fhcrc.org/ science/labs/breeden/cellcycle), where the new data sets can be viewed and our rankings can be directly compared with previous analyses.

Fifty-seven TFs rank in the top 1000 in either PNM5 or PBM5. Figure 1A shows heat maps of the transcription profiles for these genes, ordered with respect to their average peak time. About half are newly designated as periodic (asterisks in Fig. 1A). Among these cell cycleregulated TFs are two involved in regulation of hexose transport genes (Pdr1 and Mth1) (Nourani et al. 1997.
Schmidt et al. 1999|, Msn2 and Msn4, which partner to regulate transcription in response to stress (MartinezPastor et al. 1996) and four factors known to be involved in cell cycle-regulated transcription (Hir1 and Hir2 [Osley and Lycan 1987], Mbp1 [Koch et al. 1993], and Fkh2 [Zhu et al. 2000]).

Figure 1B summarizes the global pattern of cell cycleregulated transcription. This analysis required alignment of the time scales and start points from five different data sets. As a result, the output is shown as a percent of the cell cycle with zero arbitrarily defined as the M/G1 transition. The largest group of cell cycle-regulated transcripts peak from $17 \%$ to $27 \%$ of the cell cycle,
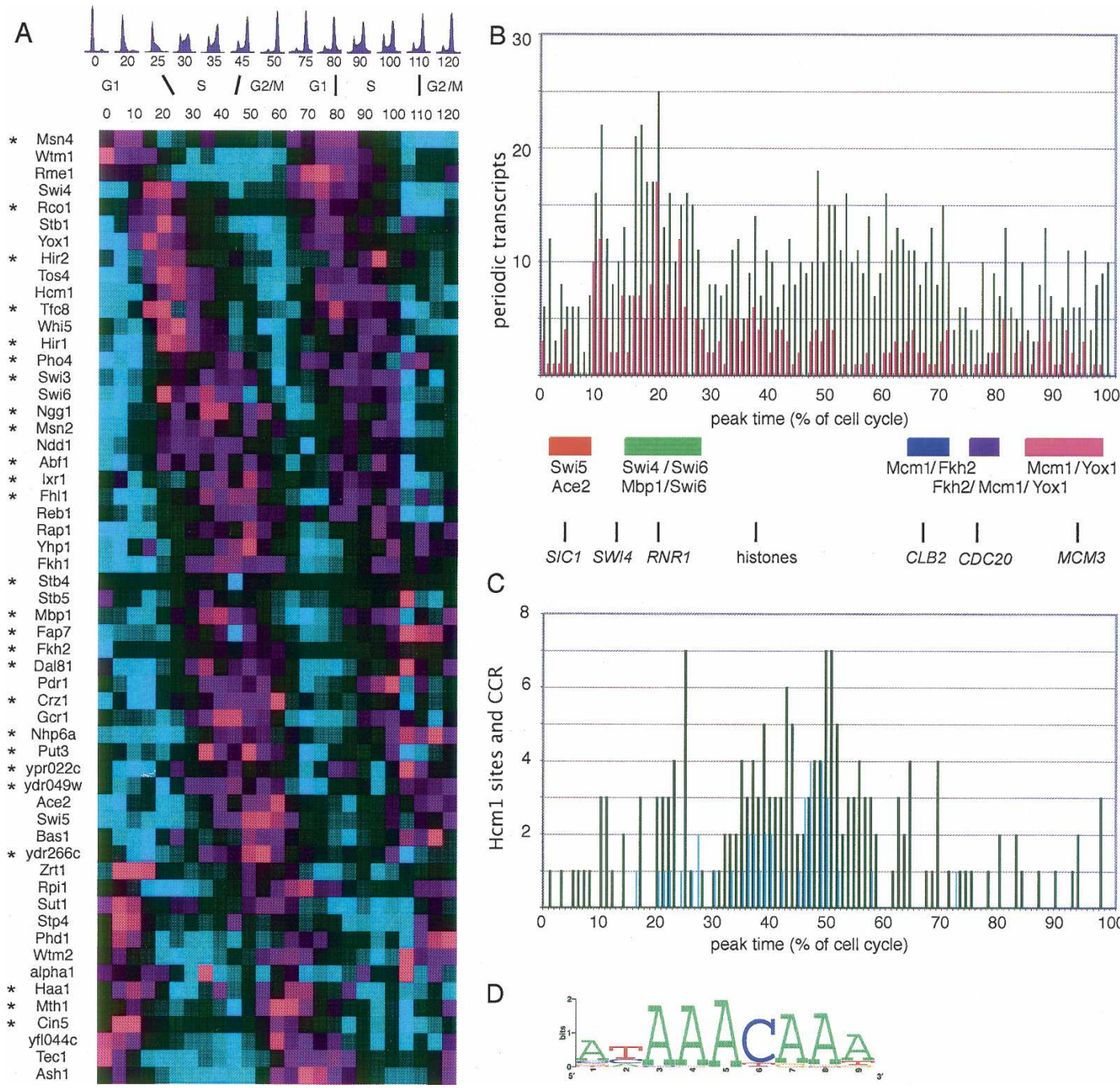

C

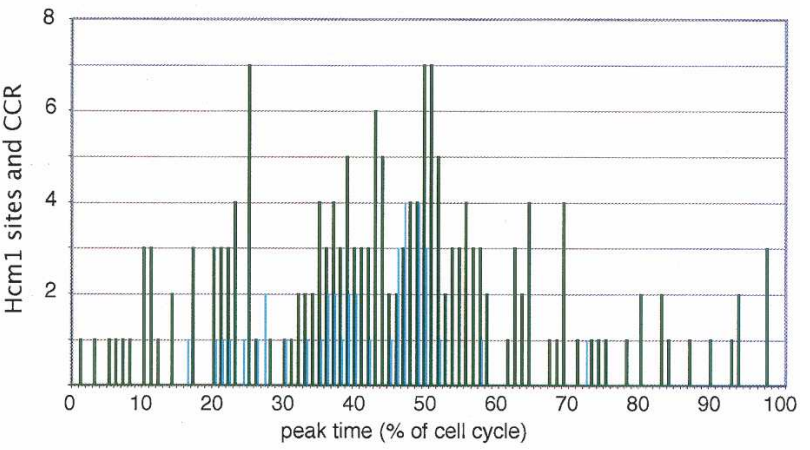

D

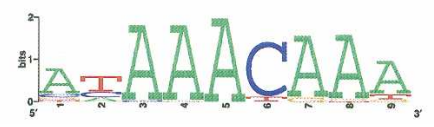

Figure 1. Periodic transcription during the S. cerevisiae cell cycle. (A) Heat map of $\alpha 30$ microarray data through two cell cycles showing 57 TFs that have been identified as being periodic by PNM5 or PBM5 analysis. Asterisks indicate transcripts not previously viewed as periodic. Names of the TF corresponding to each row are listed on the left, while each time point is represented by a column. The peak transcript level is magenta, troughs are cyan, and black represents no change compared with an asynchronous culture. The progress of the cell cycle in these cells, as monitored by FACS, is indicated at the top. (B) Histogram showing the distribution of the average peak expression times of the top 1000 periodic genes from PBM5 as a percent of the cell cycle, with zero time defined as the M/G1 transition (de Lichtenberg et al. 2005b). The top 300 ranked genes are indicated in magenta. Histones serve as a landmark of S phase and peak at $37 \%$. TFs active during specific phases are indicated below. (C) Average peak expression times of 180 potential Hcm 1 target genes. The distribution of the 40 HCM1 targets identified in the initial PhyME result are in cyan. $(D)$ WebLogo (Crooks et al. 2004) for the consensus Hcml-binding site used to search the genome for conserved Hcml target genes. 
which corresponds to late G1 and early S, when Swi4, $\mathrm{Mbp} 1$, and Swi6 induce transcription of many genes involved in DNA synthesis and budding. These late G1 transcripts are also the most enriched group among those that rank in the top 300 by PBM5 (Fig. 1B, magenta bars). Histone mRNA levels peak at $37 \%-39 \%$ and serve as a marker for early $\mathrm{S}$ phase.

\section{Identifying an S-phase-specific promoter element}

In order to investigate S-phase-specific transcription, we searched for phylogenetically conserved sequences within the promoters of genes whose transcripts peak during $S$ phase. We started with the most periodic 657 transcripts identified by PNM5 and eliminated those that contained conserved binding sites for the late G1 TFs and FKH-binding sites. The remaining 252 transcripts were partitioned by peak times, and then PhyME (Sinha et al. 2004) was used to search through the aligned sequences of orthologous promoters from related species to identify phylogenetically conserved and overrepresented motifs. Table 1A shows the highest-scoring motifs for seven overlapping partitions bracketing $S$ phase. The core sequence TAAACAA was identified in every run, and 40 genes containing this motif in their promoters were identified. The distribution of these 40 peak times is shown in Figure $1 \mathrm{C}$ in cyan. Interestingly, almost half of these genes are involved in chromosome segregation. Four microtubule motor proteins (PAC11, CIN8, KIP1, and VIK1), four components of the kinetochore (DUO1, DSN1, NSL1, and SPC34), and many genes involved in sister-chromatid cohesion and spindle dynamics (ESP1, SPC98, SPC29, and TUB2) were identified. A position-specific probability matrix derived from these promoters was generated (Supplementary Table S1), which identified the 9-base consensus sequence shown in Figure 1D. This matrix was then used to find conserved occurrences of this motif genome-wide. Fourhundred-thirteen promoters contained this conserved AT-rich sequence with a threshold score $>14$, and 180 of these transcripts were classified as cell cycle regulated by both PNM5 and PBM5 (Supplementary Fig. S3). The peak times for these 180 transcripts (Fig. 1C, black bars) form a broad peak corresponding to late $S$ phase, from $33 \%$ to $57 \%$ of the cell cycle.

Hcm1 is an S-phase-specific transcription factor whose targets are required for chromosome segregation and budding

The consensus sequence identified in these 180 transcripts (Fig. 1D) matches the core sequence of the 11base-pair (bp) binding site identified in vitro (WAAYA AACAAW) for Hcml (Zhu and Davis 1998). We have cloned the consensus binding sites from the S-phase-specific WHI5 transcript into a lacZ reporter construct. Figure 2 shows the activity of this promoter element across two cell cycles. The lacZ message driven by this element is periodic and peaks at 40-50 and then 100-110 min in wild-type cells. This timing corresponds to late $S$ phase (see Fig. 1). Its activity drops to a low constitutive level in hcm 1 cells (Fig. 2) and is undetectable when point

Table 1A. PhyMe results: S-phase-specific transcripts

\begin{tabular}{|c|c|c|c|c|c|}
\hline$t_{1 / 2} \max$ & $\begin{array}{l}\text { Total number } \\
\text { of genes }\end{array}$ & First motif & Scores & Second motif & Scores \\
\hline $7-11$ & 33 & $\mathrm{~A} A C G C G A \mathrm{~A}$ & $107 / 6.7$ & ACAAACAA & $66 / 8.1$ \\
\hline 10-14 & 28 & TAAACAAA & $77 / 8.2$ & TTTCGCGT & $67 / 8.3$ \\
\hline $12-16$ & 25 & TAAACAAA & $85 / 8.1$ & TTTCGCGT & $60 / 9.4$ \\
\hline $15-19$ & 25 & ATAAACAA & $57 / 7.4$ & AAAAAAAA & $43 / 7.3$ \\
\hline $17-21$ & 27 & GTAAACAAA & $82 / 8.1$ & TAGCCGCC & $53 / 8.4$ \\
\hline $20-24$ & 37 & TAAACAAA & $90 / 8.1$ & СTCATCGC & $62 / 8.8$ \\
\hline $22-26$ & 50 & TAAACAAA & $89 / 8.1$ & TATATATA & $80 / 7.8$ \\
\hline
\end{tabular}

Transcripts were partitioned by the time to half maximal level calculated from the PNM curve fits in the $\alpha 30$ data set. Bold letters indicate the HCM element. Italicized sequences in the first three bins are related to the late G1-specific MCB element (McIntosh et al. 1991). The italicized sequence in the 20-24 bin is a PAC element (Sudarsanam et al. 2002). The two motifs with the highest PhyME scores (Sinha et al. 2004) are reported.

Table 1B. Enrichment categories for potential Hcm1 target genes

\begin{tabular}{lcc}
\hline Component & P-value & Target genes \\
\hline Spindle pole body & $1.78 \mathrm{E}-11$ & SPC42 DUO1 SPC29 SPC97 NUD1 KAR3 BFA1 SPC98 KIP1 CLB4 TUB2 MPS1 \\
& TUB1 CIK1 NUF2 SPC34 \\
Kinetochore & $1.29 \mathrm{E}-06$ & DUO1 IPL1 CIN8 NSL1 DAM1 NDC80 ASK1 DSN1 MPS1 NUF2 SPC34 \\
Cytoskeletal motor & $8.12 \mathrm{E}-10$ & PAC11 CIN8 KAR3 KIP1 MYO2 KIP3 CIK1 DYN1 MYO1 VIK1 \\
Bud & $7.72 \mathrm{E}-09$ & AMN1 BUD9 DSE1 BNI5 SVL3 BOI1 SRL1 YMR295C CIS3 CDC11 RHO1 HSL7 \\
& TCB3 NUM1 BUD4 CDC5 MYO1 YOL070C
\end{tabular}

The enrichment categories for the list of 180 putative Hcm 1 targets were calculated using the GO Term Finder (Ashburner et al. 2000). 


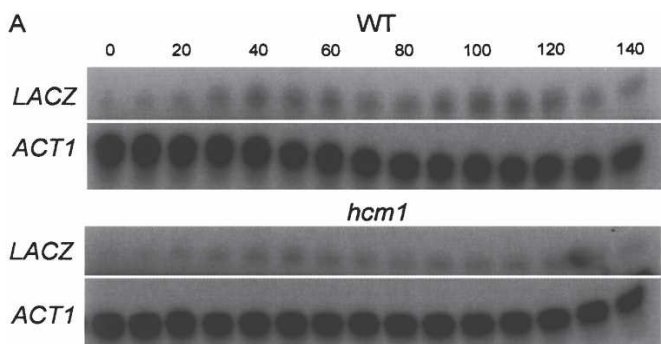

B
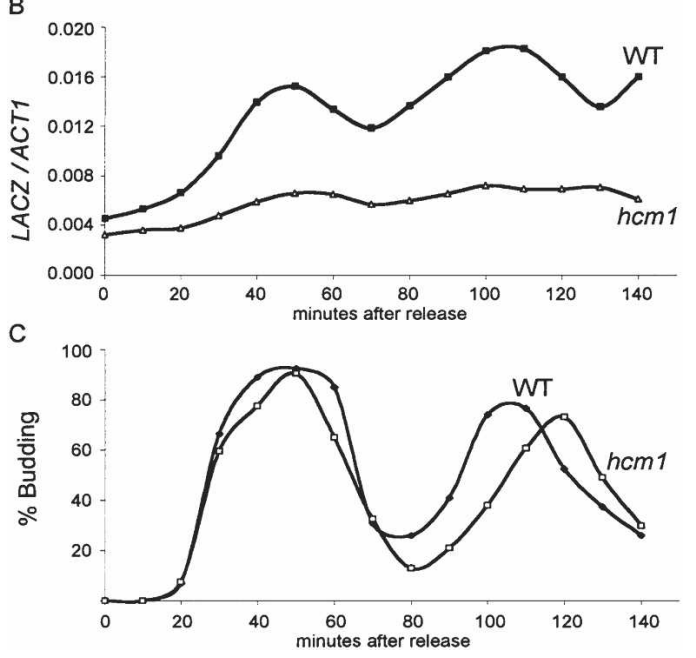

Figure 2. Cell cycle regulation by the HCM element. (A) S1 transcript analysis of LacZ mRNA from a LacZ reporter containing the HCM sites from WHI5 in wild-type (WT) and hcm1 cells. (B) Quantitation of the gels in $A$, showing the loss of cell cycle periodicity in $h \mathrm{~cm} 1$ cells. $(C)$ Budding index of wild-type (WT) and hcm1 cells.

mutations disrupt the sequence (data not shown; see Materials and Methods). These results demonstrate that this "HCM" element is necessary and sufficient to confer cell cycle-regulated transcription that peaks in late $S$ and is Hcml-dependent.

The 180 putative Hcm 1 targets show a highly significant enrichment for components of the spindle, chromosome organization, and budding (Table 1B). Bud emergence occurs during $\mathrm{S}$ phase, as does kinetochore assembly and new spindle pole body (SPB) formation (Tanaka et al. 2005). It was therefore of interest to see that 18 components of the bud, $16 \mathrm{SPB}$ proteins and most of the microtubule motor proteins, were among the putative targets of Hcm1. Kinetochore proteins are also prominent among the potential Hcm 1 targets. To verify some of these targets, we followed their transcription profiles through the cell cycle. CIN8, SPC34, and DSN1 are clearly periodic in wild-type cells (Fig. 3A,B), but their mRNA levels are reduced and almost constitutive in hcm 1 mutant cells. This is not due to a loss of synchrony because the budding profiles of hcm 1 and wild-type cells as they traverse the cell cycle are comparable (Fig. 3C). We conclude that Hcm 1 is required for the S-phase-specific transcription of these genes.

Hcml-binding sites have been investigated by ge- nome-wide chromatin immunoprecipitation (ChIP), and 10 of our putative Hcm 1 targets were identified in that study (Horak et al. 2002). We have reconfirmed that one of these targets, CIN8, is a binding site for $\mathrm{Hcm} 1$ in vivo (Fig. 3D). However, the 237 other putative Hcm1-bound promoters found by Horak et al. do not contain the conserved HCM element, nor do they show a significant enrichment for genes involved in chromosome segregation and budding based on their GO annotations (L.L. Breeden, unpubl.). Unfortunately, genome-wide ChIP assays have not been very successful in identifying known targets of the late G1 TFs (Bean et al. 2005) or of the M/G1-specific Yox1 protein (Pramila et al. 2002). It seems that these transiently active transcription complexes are especially challenging for genome-wide ChIP analysis.

\section{Hcm1 also regulates other cell cycle-specific transcription factors}

Among the genes containing conserved HCM elements are several genes that encode cell cycle-specific TFs. These include the repressor of late G1 transcription, Whi5, and another repressor, Yhp1, which restricts the timing of M/G1-specific transcription. Two members of the forkhead family of TFs, Fkh1 and Fkh2, and Ndd1, which associates primarily with Fkh2 at M-specific promoters, are also among Hcml's potential targets. To determine whether $\mathrm{Hcm} 1$ is responsible for the periodic transcription of these genes, we followed their mRNA levels through the cell cycle in hcm 1 and wild-type cells. As a synchrony control, we analyzed $R N R 1$ transcription and note that its profile is unaffected by hcm1 (Fig. 4A). However, the mRNA profiles for these cell cycle-specific TFs are all affected to varying extents. WHI5 and NDD1 both peak at 40 and $100 \mathrm{~min}$ in the two consecutive cell cycles in wild-type cells and both display a constitutive, basal level of mRNA across the same time course in hcm 1 cells (Fig. 4B). YHP1, which peaks at the same time as WHI5 and NDD1 in wild-type cells, retains periodicity but has a peak delay of $\sim 10 \mathrm{~min}$ in hcm 1 cells (Fig. 4A). FKH1 and FKH2 also retain periodicity, but their maximum levels are reduced, and they suffer a slightly longer delay in the hcm 1 mutant (Fig. 4C). These TFs are clearly deregulated by loss of Hcm 1 and are likely to be direct targets as they have Hcm1-binding sites in their promoters. However, we have been unable to verify in vivo binding by Hcm 1 to these promoters, possibly due to the very low and transient expression of $\mathrm{Hcm} 1$ (Ghaemmaghami et al. 2003; see below).

\section{Hcm1 protein is periodically expressed and post-translationally regulated}

HCM1 transcription is cell cycle regulated (Cho et al. 1998). Its transcription peaks in late G1 (Fig. 1A), and both of the late G1 transcription factor complexes (Swi4/ Swi6 and Mbp1/Swi6) bind the HCM1 promoter (Iyer et al. 2001; data not shown). To see if Hcm 1 protein levels are also restricted within the cell cycle, we have fol- 
Figure 3. Hcm 1 regulates cell cycle expression of DSN1, CIN8, and SPC34. (A) S1 nuclease protection assays for DSN1, CIN8, and SPC34 showing periodic expression in wild-type HCM1 and deregulation in hcm1 yeast cells. ACT1 was used as a loading control. $(B)$ Quantification of gels shown in $A$ plotted as a ratio of variant transcript over control (ACT1). (C) HCM1 and $h \mathrm{~cm} 1$ budding profiles. $(D) \mathrm{ChIP}$ analysis: binding of Flag-tagged $\mathrm{Hcm} 1$ to the CIN8 promoter. ACT1 serves as negative control (NC).
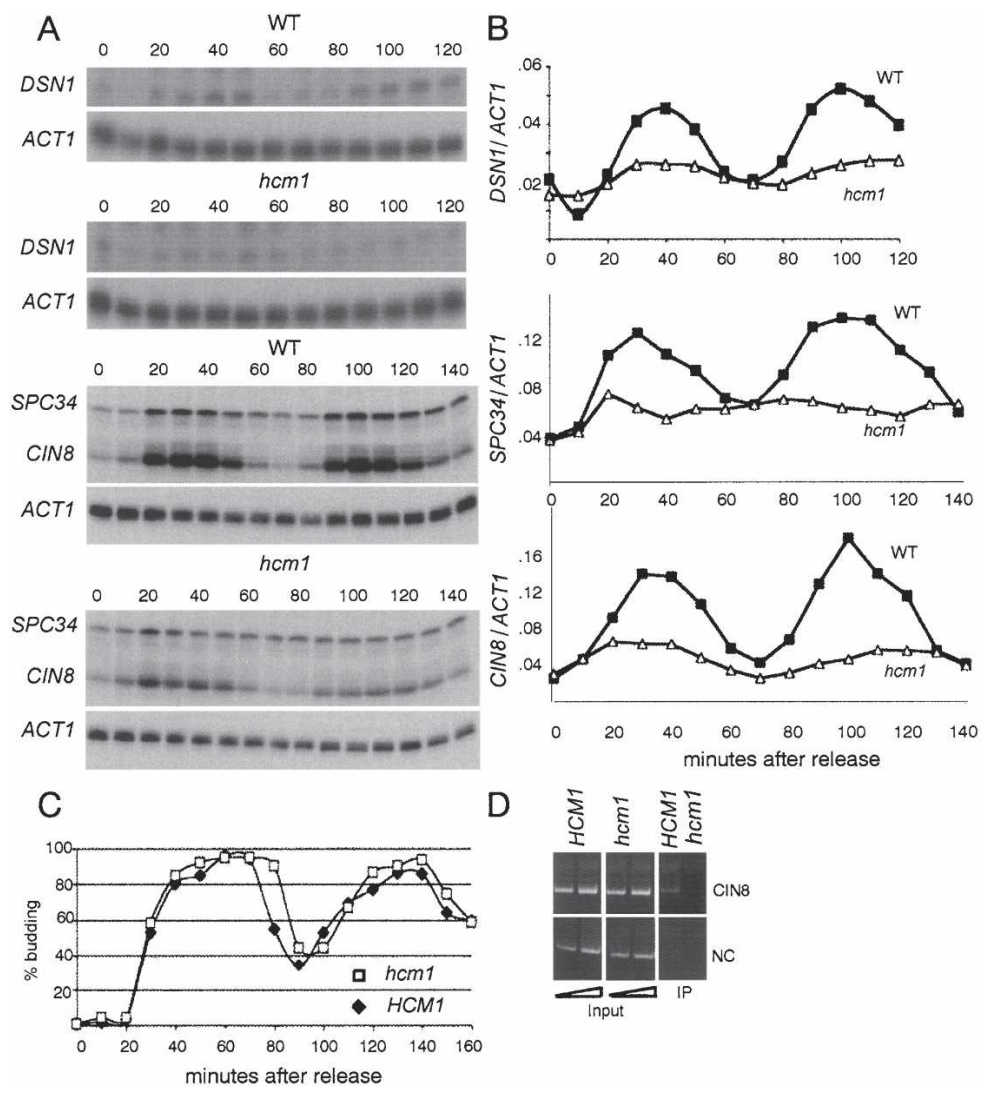

D

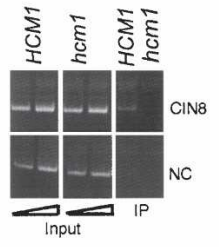

lowed tagged $\mathrm{Hcm} 1$ across the cell cycle (Fig. 5A,B) and find that $\mathrm{Hcm} 1$ protein is also periodically expressed in a pattern that correlates with its mRNA profile.

To see if the periodic expression of Hcml is responsible for the periodic expression of its target genes, we fused the HCM1 open reading frame to the constitutive GAL1 promoter. When this construct replaces the endogenous HCM1 gene, the Hcm 1 protein is constitutively expressed (Fig. 5B). However, cell cycle regulation of two Hcm 1 targets (WHI5 and NDD1) is still evident in these cells (Fig. 5C,D). We conclude that there is an additional post-translational component that regulates Hcml activity.

\section{Chromosome segregation is impaired in the absence of $\mathrm{Hcm} 1$}

If $\mathrm{Hcm} 1$ regulates transcription of genes involved in chromosome segregation, we would expect loss of $\mathrm{Hcm} 1$ activity to be deleterious. This is not apparent from its budding kinetics under optimal growth conditions, where it almost mirrors the wild-type profile (Fig. 3C). However, we have monitored the fidelity of chromosome transmission with a sectoring assay (Spencer et al. 1990). The red sectors indicate that nearly every colony has suffered multiple loss events (Fig. 6A). We have calculated the chromosome loss rate per generation to be at least 10 -fold elevated in $h \mathrm{~cm} 1$ mutants $(0.2 \pm 0.03 \%$ loss per generation for $h c m 1$, compared with $0.02 \pm 0.01 \%$ for wild type).
We also monitored the DNA content of $h \mathrm{~cm} 1$ cells as they traverse the cell cycle (Fig. 6B). The hcm1 cells enter S phase faster than wild type, but they spend a longer time in G2/M. The early S-phase entry is not understood, but it could contribute to the genetic instability of this strain (Sidorova and Breeden 2003). The G2 delay could be due to activation of the DNA damage checkpoint (Foiani et al. 2000) or the spindle checkpoint, which delays mitosis until chromosomes are properly aligned (Straight and Murray 1997). The accumulated evidence supports the latter explanation. $\mathrm{hcm} 1$ mutants are not hypersensitive to the block to replication caused by hydroxyurea (HU), nor do they require a functional DNA damage checkpoint for viability (data not shown). In contrast, $h \mathrm{~cm} 1$ deletions are sensitive to the spindle poison benomyl (Horak et al. 2002; Daniel et al. 2006), and they are synthetically lethal with mad1, mad2, and pds1, which disrupt the spindle checkpoint (Sarin et al. 2004; Tong et al. 2004; Daniel et al. 2006). The simplest interpretation of these observations is that the chromosome segregation defects that arise due to suboptimal expression of Hcml target genes activate the spindle checkpoint and are sufficient to kill cells that lack the ability to recognize and repair them.

\section{Discussion}

Combined analysis of new cell cycle microarray data and three previously collected data sets enabled us to iden- 


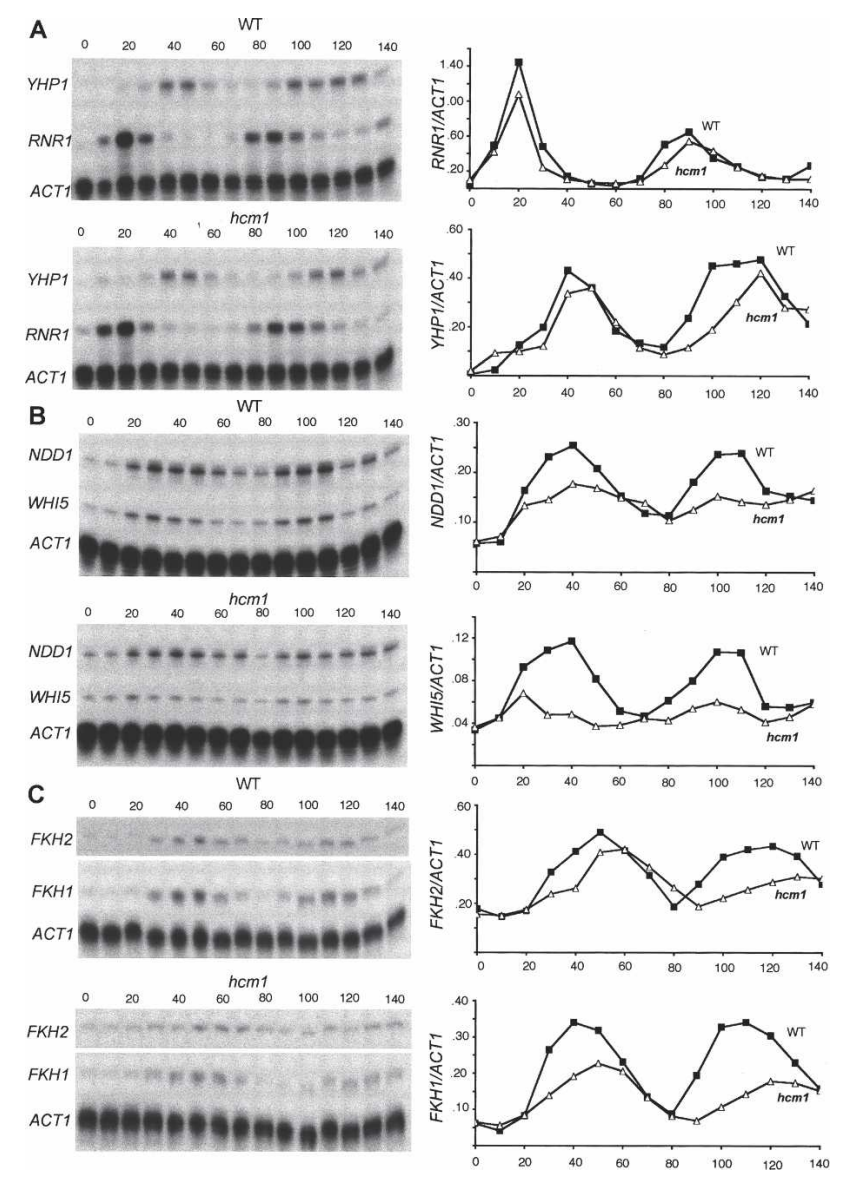

Figure 4. Hcm 1 regulates expression of five TFs. The left panel shows the S1 nuclease protection assays through the cell cycle in wild-type and hcml cells, and the right panel shows the quantification of those gels for YHP1 $(A), N D D 1$ and WHI5 (B), and $F K H 1$ and $F K H 2(C)$. The target RNA were normalized with the actin (ACT1) RNA and plotted as a ratio.

tify periodic transcripts with higher confidence than before. Performance testing indicated that PBM5 analysis, which takes into account both periodicity and the magnitude of the oscillation, performs the best. As expected, the highly periodic transcripts are easily identified. We find almost perfect agreement between PNM5, PBM5, and the Spellman list (Spellman et al. 1998) for the 300 highest-ranking transcripts. However, among the topranked 600 periodic transcripts based on PBM5, onequarter (142 transcripts) are newly discovered periodic transcripts. This highlights the extent to which the new PBM5 list differs from previous findings and identifies new, highly periodic transcripts.

Our interest is in defining the regulatory circuits responsible for cell cycle-regulated transcription. To do this, we have calculated a weighted average peak time for each transcript. Because this peak time is based on all five data sets, it is our most reliable means to characterize the expression pattern for individual transcripts. Moreover, it can be used to partition transcripts into discrete time intervals with the goal of identifying coordinately regulated genes. These peak times form a con- tinuum (Fig. 1B) with no evidence of global transcriptional repression during mitosis as is observed in metazoans (Gottesfeld and Forbes 1997). Throughout S phase, there is a substantial amount of periodic transcription (Fig. 1B) and roughly half of the periodically transcribed TFs peak during this interval (Fig. 1A), and yet little is known about the mechanisms of regulation during $S$ phase.

To see if we could fill this gap, we analyzed the promoters of genes with peak times around the time of histone transcription. In our initial study, we focused on a subset of transcripts with high probability of being cell cycle regulated and eliminated those containing known cell cycle regulatory elements. We then looked for sequences that were evolutionarily conserved and overrepresented in these promoters. The motif that we identified is striking in that it was the highest-scoring motif in six runs, despite being a highly AT-rich sequence embedded within yeast promoters that are AT-rich overall. This motif was not identified in the genome-wide searches for phylogenetically conserved promoter motifs (Kellis et al. 2003; Harbison et al. 2004). We conclude that identifying a tight group of coordinately regulated transcripts was critical to the success of this strategy.

The TF that binds to this motif, Hcml, was first identified as a high-copy suppressor of a defect in spindle pole assembly (Zhu et al. 1993). The Hcm1-binding site was characterized by site selection (Zhu and Davis 1998) and then found in the promoters of four genes involved in spindle function. However, $h \mathrm{~cm} 1$ mutants did not affect the steady-state level of these mRNAs. SPC110 mRNA was followed through the cell cycle, and it was shown that $h \mathrm{~cm} 1$ reduces the maximum level of SPC110 transcript, but it does not eliminate its periodicity (Zhu and Davis 1998). The persistence of cell cycle regulation was attributed to the presence of an MCB element in the SPC110 promoter (Zhu and Davis 1998), and as a result the role of $\mathrm{Hcm} 1$ in cell cycle regulation was obscured.

Perhaps because we initially excluded transcripts that had other cell cycle-regulated elements in their promoters, we were able to identify genes for which $\mathrm{Hcm} 1$ is unambiguously responsible for their periodic transcription. SPC34, CIN8, DSN1, NDD1, and WHI5 mRNAs are constitutive in $\mathrm{hcm} 1$ cells. These transcripts peak between $35 \%$ and $48 \%$ of the normal cell cycle. The HCM reporter construct produces peak levels of lacZ mRNA slightly later $(53 \%)$. Since peak values will vary depending on the stability of the mRNA, $35 \%-53 \%$ is a reasonable approximation of when $\mathrm{Hcm} 1$ is activating HCM elements. Our candidate $\mathrm{Hcm} 1$ targets show a broader distribution, but the distribution of peak times is clearly centered on this range. Those candidates with peaks well beyond this range will no doubt include some false positives as well as some genes under different forms of combinatorial control.

Combinatorial control by multiple promoter elements is very common (Lee et al. 2002), and with cell cycle regulatory elements they have been shown to influence the timing of the resulting peak. The presence of $\mathrm{MCB}$ and ECB elements in the SWI4 promoter (McInerny et al. 

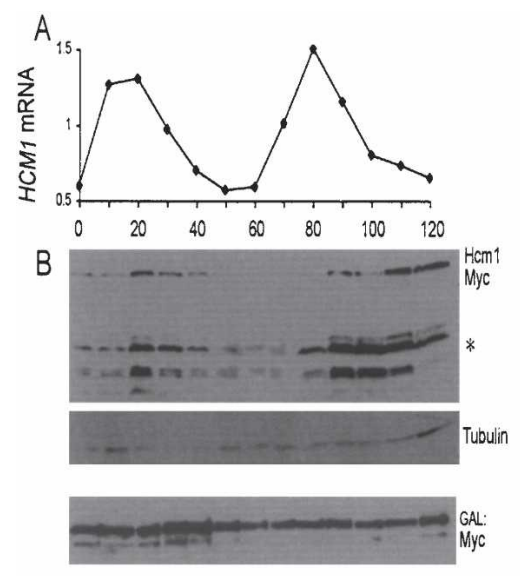
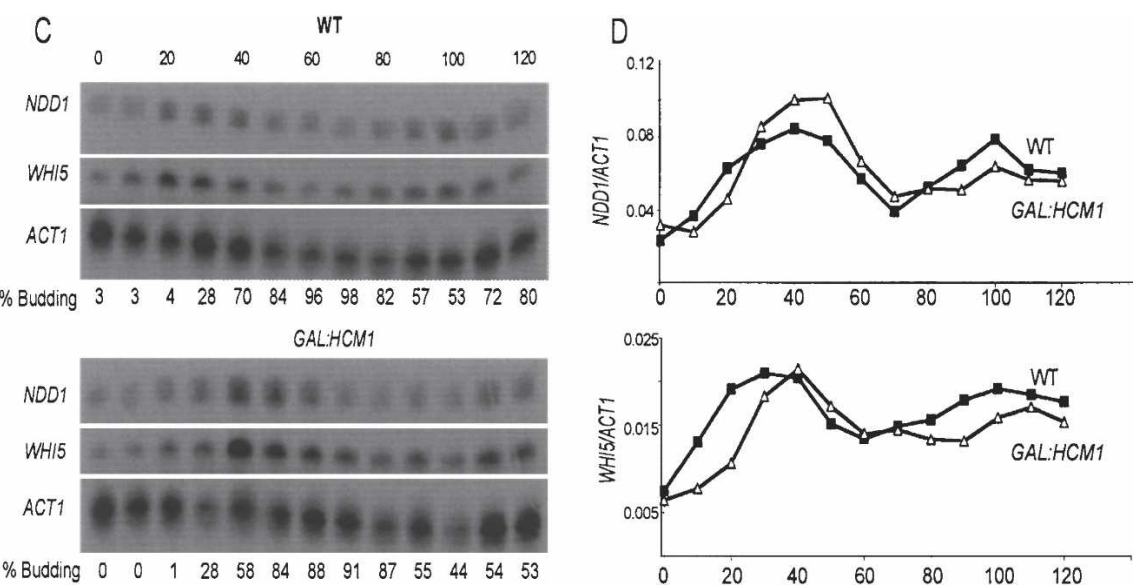

Figure 5. Periodicity of HCM1 transcript and Hcm 1 protein levels. (A) Quantitative S1 of HCM1 mRNA through the cell cycle. (B) Immunoblots showing the levels of Myc-tagged Hcm 1 and of Myc-tagged Hcm 1 under control of the GAL1 constitutive promoter monitored across the cell cycle of $\alpha$-factor synchronized wild-type (WT) cells. Asterisk indicates additional bands that could be either breakdown products or shortened active versions of the protein. (C) S1 gels showing mRNA profiles of Hcm1 targets (WHI5 and NDD1) through the cell cycle in the presence of GAL:HCM1 or wild-type HCM1. The synchrony of these two cell cycles, as indicated by percentage of budded cells, is shown underneath the panels. (D) Quantitation of the gels shown in $C$.

1997) results in a peak at $14 \%$ compared with an MCBregulated, late G1 transcript like CDC45 (18\%) (Bean et al. 2005) or an ECB-regulated, M/G1-specific gene like MCM3 (94\%). The presence of both Yox- and Fkh-binding sites flanking the Mcml-binding site in the CDC20 promoter (Pramila et al. 2002) shifts its peak to $77 \%$, between CLB2 (66\%) and MCM3 (94\%), which are regulated by either Fkh/Mcml or Mcm1/Yox sites, respectively (Fig. 1B). In the case of Hcml targets, there is a large group of genes with transcript peaks from $20 \%$ to $26 \%$ of the cell cycle (Fig. 1C). Fifteen out of 18 of these genes also contain an MCB or SCB element, which is most likely responsible for this early peak. The shift in peak timing of YHP1, FKH1, and FKH2 in hcm 1 mutants is also indicative of combinatorial control by Hcml and at least one other cell cycle-specific regulator that promotes transcription later in the cycle.

The HCM1 transcript is also cell cycle regulated and peaks in late G1 phase. Thus, Hcm 1 conforms to the same general pattern observed for other cell cycle-specific TFs in that they are maximally expressed just before they act, and their targets are made when they are needed. The transient expression of Hcm 1 may account for the fact that only 10 of the 180 potential Hcm 1-regulated genes were identified by genome-wide ChIP, which was carried out with asynchronous cells (Horak et al. 2002). However, the transient expression of Hcm 1 is not required for the transient transcription of its target genes. Our evidence indicates that there is at least one additional post-translational regulatory step in activating Hcm 1. Hcm 1 is a probable Cdk target (Ubersax et al. 2003), and there are 12 potential Cdk sites in its coding sequence. Hcm 1 has also been shown to associate with Cdk and the M-phase cyclin Clb2 in genomic studies (Ubersax et al. 2003). Now that we have placed Hcm 1 in the transcriptional circuitry of the cell cycle, it will be important to identify its proximal regulators.
This study of Hcml targets has identified two new clusters of coordinately regulated proteins with related functions. Eighteen of the potential Hcml targets are involved in budding. Budding is initiated at about the same time as DNA synthesis (Pringle and Hartwell 1981). Interestingly, there are many budding genes that are transcribed in late G1, then another set that are transcribed later and are likely to be regulated at least in part by HCM elements. It will be interesting to see if the members of these groups perform temporally distinct functions. hcm 1 cells do not show any marked budding defects, but they do show reduced fitness after prolonged growth in rich medium (Deutschbauer et al. 2005) and a growth defect in nonfermentable carbon sources (Steinmetz et al. 2002).

Nearly half of the 180 putative Hcm 1 targets are involved in chromosome organization and spindle dynamics. Their coordinate expression during late $S$ phase and shared HCM sites suggest that these genes also form a cluster of coregulated genes. Here again, their time of expression is appropriate. Several events occur during $S$ phase that are critical for proper chromosome segregation. Centromeres remain attached to the microtubules during most of the cell cycle except during $S$ phase when kinetochores are disassembled to facilitate centromere replication (Winey and O'Toole 2001; Pearson et al. 2004). Kinetochores are then reassembled and captured by the microtubules (Tanaka et al. 2005), and assembly of a new SPB is initiated (Adams and Kilmartin 2000; Winey and O'Toole 2001). For faithful chromosome segregation to occur, the mitotic spindle must be positioned perpendicular to the mother-bud neck (Yeh et al. 2000). The sister kinetochores biorient, a bipolar spindle is formed, and the sister chromatids are pulled toward the opposite spindle poles (Janke et al. 2002; Dewar et al. 2004). Suboptimal expression of any component of these processes could lead to the elevated chromosome loss 

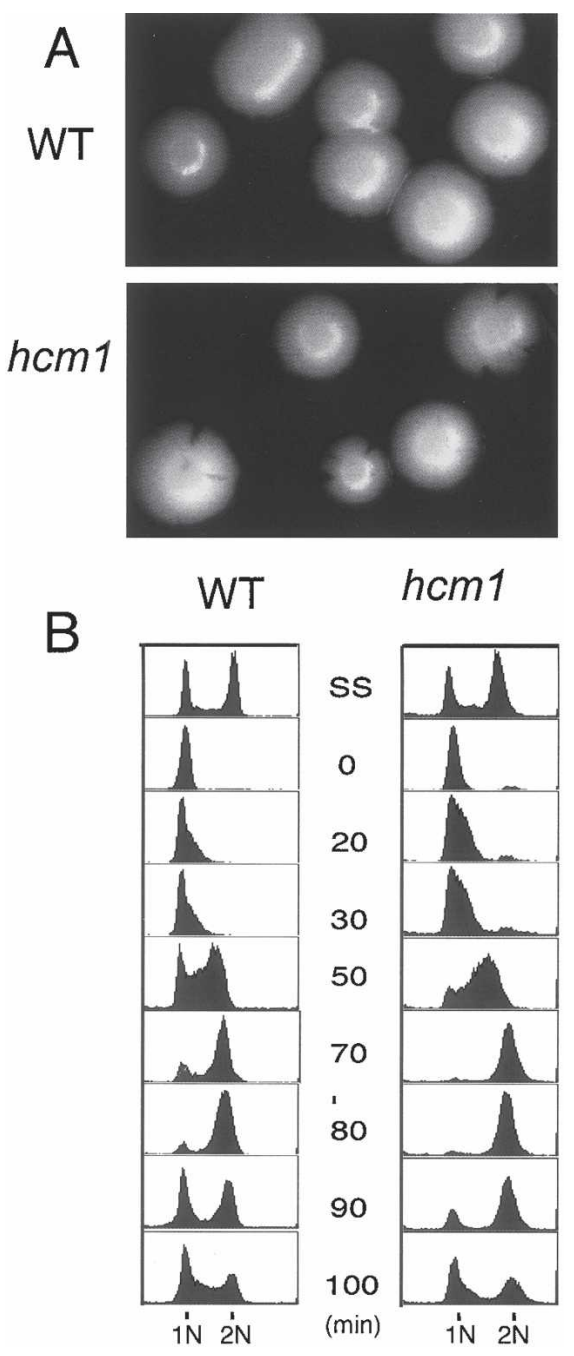

Figure 6. Genomic instability in $h \mathrm{~cm} 1$ cells. (A) Increased chromosome loss in hcm1 cells compared with wild type (WT) can be visualized as sectoring or dark clonal patches in colonies. (B) FACS across the cell cycle in wild-type and hcm 1 cells.

and dependence on the spindle checkpoint that is observed in hcm1 cells (Sarin et al. 2004; Tong et al. 2004; Daniel et al. 2006).

hcm 1 mutants also require the activity of the dynactin complex (Tong et al. 2004), which is involved in spindle orientation and nuclear migration (Schroer 2004). Five mutants in the dynactin pathway are either lethal or highly deleterious in an hcm1 background (Tong et al. 2004). Interestingly, four of these genes (JNM1, DYN1, NUM1, and BIK1) were also identified in a screen for PAC mutants that Perish in the Absence of Cin8 (Geiser et al. 1997). Now, we can offer a plausible explanation for the interactions between $h \mathrm{~cm} 1$ and $P A C$ genes because $\mathrm{Hcm} 1$ is a direct activator of CIN8 transcription.

$\mathrm{Hcm} 1$ is one of four budding yeast forkhead TFs, based on the presence of the conserved DNA-binding domain (Kaestner et al. 2000). Thus, there could be some overlap in binding specificities. Fhll binds to ribosomal protein promoters (Lee et al. 2002), but its binding site has not been identified. The two other forkhead proteins, Fkh1 and Fkh2, bind to a sequence related to the Hcm1-binding site (GTAAACA), and fkh2 and fkh1fkh2 mutants exhibit defects in spindle structure (Pic et al. 2000). Sixteen of the 180 potential $\mathrm{Hcm} 1$ targets peak late and are significantly deregulated in the fkh1fkh2 mutant (Zhu et al. 2000; Bar-Joseph et al. 2003). These may be false positives in our search, but they represent $<10 \%$ of putative $\mathrm{Hcm} 1$ targets. Moreover, the genes deregulated in fkh1fkh2 cells are not enriched for genes involved in chromosome segregation or budding as are the potential $\mathrm{Hcm} 1$ targets, so the overlap, if any, is minimal.

Hcml represents the third member of the yeast forkhead family that plays an important role in cell cyclespecific transcription and in the transcriptional regulatory network that underlies the yeast cell cycle. Figure 7 shows this regulatory circuit and the gap filled by Hcm 1 . $\mathrm{Hcm} 1$ is transcribed by the late G1 transcription complexes. In addition to activating the S-phase-specific expression of genes involved in budding and chromosome segregation, $\mathrm{Hcm} 1$ also activates WHI5, which is a negative regulator that limits late G1-specific transcription in the next cycle. It also activates YHP1, which represses ECB elements late in the cycle. In addition, $\mathrm{Hcml}$ is required for the timely activation of at least three TFs (Fkh1, Fkh2, and Ndd1) that activate M-phase-specific transcription. Clearly, the expression driven by Hcml is important for an optimal mitotic cycle. $\mathrm{Hcm} 1$ is not an essential gene, but it is synthetically lethal with 11 different mutants, all of which are involved in chromosome segregation and/or the spindle checkpoint that monitors that process. Even with the spindle checkpoint machin-

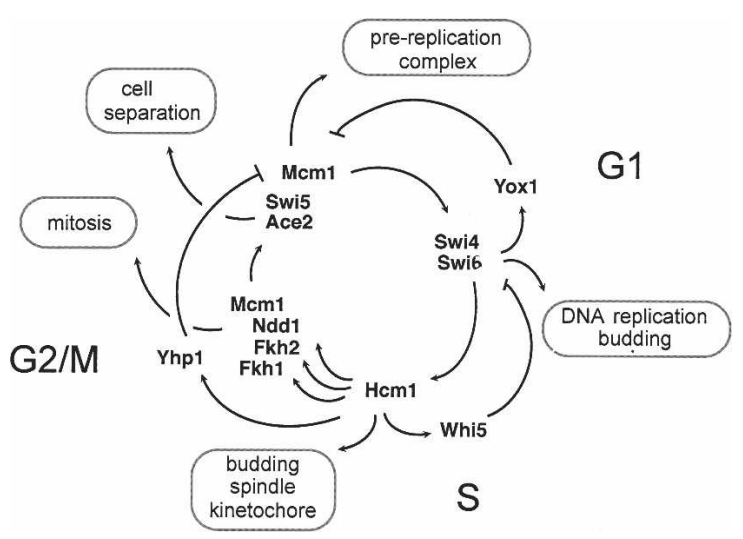

Figure 7. Hcml functions as an S-phase-specific transcriptional activator. HCM1 is activated by the Swi4/Swi6 complex. It then transcriptionally activates WHI5, which represses the subsequent round of Swi4/swi6 targets until late G1. Similarly, activation of YHP1 maintains the repression of M/G1 transcription. At the same time, activation of FKH1, FKH2, and NDD1 induces the next wave of G2/M transcription. This model connects the known cell cycle regulatory TFs to each other in a continuous cycle. However, there are hundreds of transcripts that are not targets of these factors that must be accounted for before we have a comprehensive picture of the cell cycle-regulated transcription that underlies the cell cycle. 
ery intact, $h \mathrm{~cm} 1$ cells show reduced fitness and lose chromosomes 10 times faster than wild-type cells.

More than 50 forkhead (or FOX) TFs have been identified in humans, and a few have been associated with proliferation. One of these, the human FoxM1 protein, plays a remarkably parallel role to that of budding yeast proteins Fkh1 and Fkh2. Its expression is induced at the G1/S transition (Korver et al. 1997), and it activates many of the same target genes specifically during G2 and M phase (Krupczak-Hollis et al. 2004). Its expression induces proliferation and is elevated in several forms of cancer (Wang et al. 2002; Kim et al. 2006). Recently it has been shown that FoxM1-null mutant fibroblasts are aneuploid and defective in the spindle checkpoint (Laoukili et al. 2005). Interestingly, the metazoan orthologs of many of the Hcm 1 targets are also cell cycle regulated (Whitfield et al. 2002), and some were recently shown to be down-regulated in transformed cells treated with RNAi for the FoxM1 forkhead transcription factor (Laoukili et al. 2005; Wonsey and Follettie 2005). It will be interesting to see if there is a human FOX protein that parallels the role of $\mathrm{Hcm} 1$.

\section{Materials and methods}

Strains, plasmids, and cell-based assays

Microarrays were carried out across the cell cycle with strain BY2125 (W303: MATa ade2-1 trp1-1 can1-100 leu2-3, 115 his311 ura3 ho ssd1-d). The hcm1 strain, BY4648 (GZY11-1B), and its isogenic wild type, BY4647(CRY1), used for the cell cycle S1 analysis, were obtained from T. Davis. For the chromosome loss measurements, the $h \mathrm{~cm} 1$ deletion from BY4648 was introduced by PCR into the chromosome transmission fidelity strain BY2642 (ura3-52, lys2-801, ade2-101, trp1de11, leu2del1, +CFVII [RAD2.d.YPH362] URA3 SUP11) (Spencer et al. 1990) to generate BY5349. Plasmid pGF84 containing Flag-tagged Hcm1 (a gift from T. Davis), was transformed into BY4648. The resulting strain BY5227 was used for the ChIP experiments. For following the $\mathrm{Hcm} 1$ protein across the cell cycle, the endogenous copy of HCM1 in BY4647 was tagged at the C terminus with 13-Myc epitopes (Longtine et al. 1998) to generate the strain BY5320. Constitutive expression of $\mathrm{Hcml}$ was achieved by replacing the endogenous HCM1 promoter with GAL1 promoter using pFA6a-TRP1-PGAL1 (Longtine et al. 1998). Strains thus generated were BY5731 (pGAL1:HCM1) and BY5697 (pGAL1:HCM1-13Myc). The WHI5 HCM:lacZ reporter construct was generated using the sequence AAAAAAAACAAAACAAAACAAAACAAAACAAA. The oligonucleotides were generated with 5' XhoI and 3' NotI ends, cloned into pSH144, a LacZ reporter vector, and integrated at URA3. $\beta$-Galactosidase filter assays were carried out with these reporters. Mutations in the positions indicated in bold disrupted the reporter activity.

Chromosome loss measurements were made with BY2642 and BY5349 grown overnight in minimal media lacking uracil to ensure the presence of the extra chromosome. The cells were then diluted in complete minimal media to a density of $10^{5}$ cells/mL and allowed to grow for seven to eight generations. The fully red colonies were used to calculate the chromosome loss per generation. HU sensitivity of hcm1 mutants was assayed by spotting serial dilutions of the cultures on $1 \mathrm{mM} \mathrm{HU}$ containing rich medium plates.

Cell lysates for Western blot analysis were prepared as described (Pramila et al. 2002). Briefly, cells were lysed using the
Fast Prep FP120 machine in a lysis buffer (100 mM NaCl, 20 $\mathrm{mM}$ Tris at $\mathrm{pH} 7.5,5 \%$ glycerol, $1 \mathrm{mM}$ EDTA, $1 \mathrm{mM} \mathrm{MgCl}_{2}$, and $0.1 \%$ NP-40) containing protease inhibitors. Lysates were centrifuged twice at $4^{\circ} \mathrm{C}$ for $15 \mathrm{~min}$ to separate the soluble fraction from the cell debris.

ChIP were processed as described (Pramila et al. 2002). Immunoprecipitations (IP) were done with the M2 monoclonal antibody and Protein G dynabeads. Prior to elution from the beads, the immunoprecipitates were incubated for $30 \mathrm{~min}$ at room temperature with 1 XFlag peptide (Sigma) to improve specificity. Immunoblotting for Hcml-Myc was done with the 9E-10 monoclonal antibody.

\section{Microarray hybridization, image processing}

$\alpha$-Factor synchronizations were carried out as in Breeden (1997), and the synchronized cells were sampled every 5 min for two cell cycles. RNA was extracted from these cells, and $30 \mu \mathrm{g}$ of total RNA was used for cDNA synthesis. Labelings were performed using the amino-allyl labeling protocol (http://cmgm. stanford.edu/pbrown/protocols/aadUTPCouplingProcedure.htm). To generate technical dye-swap replicates, the cDNAs from the cell cycle were labeled with Cy3 ( $\alpha 30)$ or Cy5 ( 238$)$. RNA from an asynchronous population was used as a control and labeled with the second dye. The labeled cDNAs were hybridized to yeast cDNA microarrays as described (Pramila et al. 2002). Array analysis was performed using the GenePix Pro software from Axon Instruments. For error estimation, cDNA prepared from 25-, 35-, 45-, 60-, and 100-min time points, and the asynchronous culture were labeled with Cy3 and Cy5 and then hybridized. All the microarray data were processed using an error model in the Rosetta Resolver version 3.2 Expression Data Analysis System. These data can be visualized, filtered, and sorted or downloaded (http://www.fhcrc.org/science/labs/ breeden/cellcycle). The raw data are also available at the GEO Database. The accession number for the microarray data, including both the $\alpha 30$ and $\alpha 38$ data sets, is GSE4987. RNA transcript measurements were essentially carried out as described (Pramila et al. 2002) using oligonucleotide probes.

\section{Data analysis}

For PNM analysis, the first two time points were deleted to alleviate block/release artifacts. Data points at 105 min were deleted from both data sets due to unsatisfactory hybridization. From each data set, the 1000 least variable genes and genes with $>25 \%$ missing data were discarded. The remaining genes were analyzed with PNM as described in Lu et al. (2004).

$\alpha 30$ and $\alpha 38$ data were combined for PBM analysis with three other cell cycle data sets carried out with cells synchronized by $\alpha$-factor, and temperature-sensitive mutants of CDC15 and CDC28 (Cho et al. 1998; Spellman et al. 1998). This method ranks each transcript by combining two permutation-based statistical test for periodicity and magnitude of oscillation (de Lichtenberg et al. 2005b). The method also computes a genespecific "peak time" for each transcript, describing when in the cell cycle the gene is maximally expressed.

\section{Promoter element searches}

Upstream sequences from five yeast species were collected from two previous studies (Cliften et al. 2003; Kellis et al. 2003). We searched for motifs using PhyME (Sinha et al. 2004), which takes into account aligned orthologous sequences, as well as the phylogenetic species tree. For each gene, we extracted 800 bp upstream of the start codon from each sensu stricto species 
(cerevisiae, mikitae, kudravzevii, bayanus, and paradoxus). These sequences were then aligned using Lagan (Brudno et al. 2003). For a given group of genes with similar peak times, we searched the corresponding alignments for the top two motifs, using the following options: "revcompW -ot 0.3 -maxsites 6."

For the purposes of this study, we implemented a program called Motiph that scans a multiple alignment for occurrences of a given motif. Motiph was motivated by the notion of phylogenetic shadowing (Boffelli et al. 2003), and is thus similar to Monkey (Moses et al. 2004). Given an alignment, a motif matrix, and a tree, Motiph calculates for each position in the alignment the probability of the given motif, taking into account the phylogenetic tree relating the species in the alignment. This probability is the sum of all possible evolutionary histories (i.e., all possible assignments of nucleotides to the internal nodes of the tree), with the given motif at the root of the tree. Motiph reports a log-odds score, in which the numerator is this probability (computed using a functional evolutionary rate of 1 ), and the denominator is a similar probability computed using a motif of background probabilities and a nonfunctional evolutionary rate of 1.2 .

We inferred a phylogenetic tree among the five yeast species from alignments of the coding sequences for three proteins. We selected the Mcm proteins, and used only those that could be aligned unambiguously in all five species: MCM2, CDC47, and CDC54. The concatenated alignment, consisting of 3201 columns, was analyzed using fastDNAml (Olsen et al. 1994) with the default parameters. The tree is shown in the Supplemental Material. This tree was used by Motiph and by Phyme. For input to Motiph, we wanted to generate high-quality alignments of these upstream regions, and were willing to discard unalignable sequences in order to achieve this goal. Accordingly, we designed an iterative procedure that produces upstream region alignments with pairwise percent sequence identity $>40 \%$. The procedure first removes leading single-sequence columns from the alignment, which occur frequently because the upstream regions are often of widely varying length. Thereafter, if any sequence matches poorly to the rest of the alignment, that sequence is removed, and the alignment is recomputed.

\section{Acknowledgments}

We thank U. de Lichtenberg, T. Jensen, and S. Brunak for the PBM5 computations; J. Liu, S. Sinha, and M. Tompa for access to PNM and PhyME programs; S. Guedes and E. Y. Zhan for normalization and early exploration of the microarray data with Resolver Expression Analysis System version 3.2; M. Aronszain for programming assistance; T. Davis for strains and plasmids; and J. Eichner for technical assistance. This work was funded by NIH GM41073 to L.L.B. and NIH HG003070 and NSF BDI0243257 to W.S.N

\section{References}

Adams, I.R. and Kilmartin, J.V. 2000. Spindle pole body duplication: A model for centrosome duplication? Trends Cell Biol. 10: 329-335.

Alvarez, B., Martinez, A.C., Burgering, B.M., and Carrera, A.C. 2001. Forkhead transcription factors contribute to execution of the mitotic programme in mammals. Nature 413: 744 747.

Ashburner, M., Ball, C.A., Blake, J.A., Botstein, D., Butler, H., Cherry, J.M., Davis, A.P., Dolinski, K., Dwight, S.S., Eppig, J.T., et al. 2000. Gene Ontology: Tool for the unification of biology. Nat. Genet. 25: 25-29.
Bar-Joseph, Z., Gerber, G., Simon, I., Gifford, D.K., and Jaakkola, T.S. 2003. Comparing the continuous representation of time-series expression profiles to identify differentially expressed genes. Proc. Natl. Acad. Sci. 100: 10146-10151.

Bean, J.M., Siggia, E.D., and Cross, F.R. 2005. High functional overlap between MluI cell-cycle box binding factor and Swi4/6 cell-cycle box binding factor in the G1/S transcriptional program in Saccharomyces cerevisiae. Genetics 171: 49-61.

Boffelli, D., McAuliffe, J., Ovcharenko, D., Lewis, K.D., Ovcharenko, I., Pachter, L., and Rubin, E.M. 2003. Phylogenetic shadowing of primate sequences to find functional regions of the human genome. Science 299: 1391-1394.

Breeden, L.L. 1997. $\alpha$ factor synchronization of budding yeast. Methods Enzymol. 283: 332-341.

Brudno, M., Do, C.B., Cooper, G.M., Kim, M.F., Davydov, E., Green, E.D., Sidow, A., and Batzoglou, S. 2003. LAGAN and Multi-LAGAN: Efficient tools for large-scale multiple alignment of genomic DNA. Genome Res. 13: 721-731.

Cho, R.J., Campbell, M.J., Winzeler, E.A., Steinmetz, L., Conway, A., Wodicka, L., Wolfsberg, T.G., Gabrielian, A.E., Landsman, D., Lockhart, D.J., et al. 1998. A genome-wide transcriptional analysis of the mitotic cell cycle. Mol. Cell 2: 65-73.

Cliften, P., Sudarsanam, P., Desikan, A., Fulton, L., Fulton, B., Majors, J., Waterston, R., Cohen, B.A., and Johnston, M. 2003. Finding functional features in Saccharomyces genomes by phylogenetic footprinting. Science 301: 71-76.

Cosma, M.P., Tanaka, T., and Nasmyth, K. 1999. Ordered recruitment of transcription and chromatin remodeling factors to a cell cycle- and developmentally regulated promoter. Cell 97: 299-311.

Costa, R.H. 2005. FoxM1 dances with mitosis. Nat. Cell Biol. 7: $108-110$

Costanzo, M., Nishikawa, J.L., Tang, X., Millman, J.S., Schub, O., Breitkreuz, K., Dewar, D., Rupes, I., Andrews, B., and Tyers, M. 2004. CDK activity antagonizes Whi5, an inhibitor of G1/S transcription in yeast. Cell 117: 899-913.

Crooks, G.E., Hon, G., Chandonia, J.M., and Brenner, S.E. 2004. WebLogo: A sequence logo generator. Genome Res. 14: 1188-1190.

Cross, F.R. 1988. DAF1, a mutant gene affecting size control, pheromone arrest, and cell cycle kinetics of Saccharomyces cerevisiae. Mol. Cell. Biol. 8: 4675-4684.

Daniel, J.A., Keyes, B.E., Ng, Y.P., Freeman, C.O., and Burke, D.J. 2006. Diverse functions of spindle assembly checkpoint genes in Saccharomyces cerevisiae. Genetics 172: 53-65.

de Bruin, R.A., McDonald, W.H., Kalashnikova, T.I., Yates III, J., and Wittenberg, C. 2004. Cln3 activates G1-specific transcription via phosphorylation of the SBF bound repressor Whi5. Cell 117: 887-898.

de Lichtenberg, U., Jensen, L.J., Brunak, S., and Bork, P. 2005a. Dynamic complex formation during the yeast cell cycle. Science 307: 724-727.

de Lichtenberg, U., Jensen, L.J., Fausboll, A., Jensen, T.S., Bork, P., and Brunak, S. 2005b. Comparison of computational methods for the identification of cell cycle-regulated genes. Bioinformatics 21: 1164-1171.

Deutschbauer, A.M., Jaramillo, D.F., Proctor, M., Kumm, J., Hillenmeyer, M.E., Davis, R.W., Nislow, C., and Giaever, G. 2005. Mechanisms of haploinsufficiency revealed by genome-wide profiling in yeast. Genetics 169: 1915-1925.

Dewar, H., Tanaka, K., Nasmyth, K., and Tanaka, T.U. 2004. Tension between two kinetochores suffices for their bi-orientation on the mitotic spindle. Nature 428: 93-97.

Dirick, L., Bohm, T., and Nasmyth, K. 1995. Roles and regula- 
tion of Cln-Cdc28 kinases at the start of the cell cycle of Saccharomyces cerevisiae. EMBO J. 14: 4803-4813.

Doolin, M.T., Johnson, A.L., Johnston, L.H., and Butler, G. 2001. Overlapping and distinct roles of the duplicated yeast transcription factors Ace2p and Swi5p. Mol. Microbiol. 40: 422-432.

Foiani, M., Pellicioli, A., Lopes, M., Lucca, C., Ferrari, M., Liberi, G., Muzi Falconi, M., and Plevani, P. 2000. DNA damage checkpoints and DNA replication controls in Saccharomyces cerevisiae. Mutat. Res. 451: 187-196.

Geiser, J.R., Schott, E.J., Kingsbury, T.J., Cole, N.B., Totis, L.J., Bhattacharyya, G., He, L., and Hoyt, M.A. 1997. Saccharomyces cerevisiae genes required in the absence of the CIN8encoded spindle motor act in functionally diverse mitotic pathways. Mol. Biol. Cell 8: 1035-1050.

Ghaemmaghami, S., Huh, W.K., Bower, K., Howson, R.W., Belle, A., Dephoure, N., O'Shea, E.K., and Weissman, J.S. 2003. Global analysis of protein expression in yeast. Nature 425: 737-741.

Gottesfeld, J.M. and Forbes, D.J. 1997. Mitotic repression of the transcriptional machinery. Trends Biochem. Sci. 22: 197202.

Harbison, C.T., Gordon, D.B., Lee, T.I., Rinaldi, N.J., Macisaac, K.D., Danford, T.W., Hannett, N.M., Tagne, J.B., Reynolds, D.B., Yoo, J., et al. 2004. Transcriptional regulatory code of a eukaryotic genome. Nature 431: 99-104.

Horak, C.E., Luscombe, N.M., Qian, J., Bertone, P., Piccirrillo, S., Gerstein, M., and Snyder, M. 2002. Complex transcriptional circuitry at the G1/S transition in Saccharomyces cerevisiae. Genes \& Dev. 16: 3017-3033.

Iyer, V.R., Horak, C.E., Scafe, C.S., Botstein, D., Snyder, M., and Brown, P.O. 2001. Genomic binding sites of the yeast cellcycle transcription factors SBF and MBF. Nature 409: 533538.

Janke, C., Ortiz, J., Tanaka, T.U., Lechner, J., and Schiebel, E. 2002. Four new subunits of the Dam1-Duol complex reveal novel functions in sister kinetochore biorientation. EMBO $J$. 21: 181-193.

Kaestner, K.H., Knochel, W., and Martinez, D.E. 2000. Unified nomenclature for the winged helix/forkhead transcription factors. Genes \& Dev. 14: 142-146.

Kellis, M., Patterson, N., Endrizzi, M., Birren, B., and Lander, E.S. 2003. Sequencing and comparison of yeast species to identify genes and regulatory elements. Nature 423: 241254.

Kim, I.M., Ackerson, T., Ramakrishna, S., Tretiakova, M., Wang, I.C., Kalin, T.V., Major, M.L., Gusarova, G.A., Yoder, H.M., Costa, R.H., et al. 2006. The Forkhead Box m1 transcription factor stimulates the proliferation of tumor cells during development of lung cancer. Cancer Res. 66: 21532161.

Knapp, D., Bhoite, L., Stillman, D.J., and Nasmyth, K. 1996. The transcription factor Swi5 regulates expression of the cyclin kinase inhibitor p40SIC1. Mol. Cell. Biol. 16: 5701-5707.

Koch, C., Moll, T., Neuberg, M., Ahorn, H., and Nasmyth, K. 1993. A role for the transcription factors Mbp1 and Swi4 in progression from G1 to S phase. Science 261: 1551-1557.

Koranda, M., Schleiffer, A., Endler, L., and Ammerer, G. 2000. Forkhead-like transcription factors recruit Ndd1 to the chromatin of G2/M-specific promoters. Nature 406: 94-97.

Korver, W., Roose, J., and Clevers, H. 1997. The winged-helix transcription factor Trident is expressed in cycling cells. Nucleic Acids Res. 25: 1715-1719.

Kovacech, B., Nasmyth, K., and Schuster, T. 1996. EGT2 gene transcription is induced predominantly by Swi5 in early $\mathrm{G}_{1}$. Mol. Cell. Biol. 16: 3264-3274.
Krupczak-Hollis, K., Wang, X., Kalinichenko, V.V., Gusarova, G.A., Wang, I.C., Dennewitz, M.B., Yoder, H.M., Kiyokawa, H., Kaestner, K.H., and Costa, R.H. 2004. The mouse Forkhead Box $\mathrm{m} 1$ transcription factor is essential for hepatoblast mitosis and development of intrahepatic bile ducts and vessels during liver morphogenesis. Dev. Biol. 276: 74-88.

Kumar, R., Reynolds, D.M., Shevchenko, A., Goldstone, S.D., and Dalton, S. 2000. Forkhead transcription factors, Fkh1p and Fkh2p, collaborate with Mcm 1p to control transcription required for M-phase. Curr. Biol. 10: 896-906.

Laoukili, J., Kooistra, M.R., Bras, A., Kauw, J., Kerkhoven, R.M., Morrison, A., Clevers, H., and Medema, R.H. 2005. FoxM1 is required for execution of the mitotic programme and chromosome stability. Nat. Cell Biol. 7: 126-136.

Lee, T.I., Rinaldi, N.J., Robert, F., Odom, D.T., Bar-Joseph, Z., Gerber, G.K., Hannett, N.M., Harbison, C.T., Thompson, C.M., Simon, I., et al. 2002. Transcriptional regulatory networks in Saccharomyces cerevisiae. Science 298: 799-804.

Longtine, M.S., McKenzie III, A., Demarini, D.J., Shah, N.G., Wach, A., Brachat, A., Philippsen, P., and Pringle, J.R. 1998. Additional modules for versatile and economical PCR-based gene deletion and modification in Saccharomyces cerevisiae. Yeast 14: 953-961.

Lu, X., Zhang, W., Qin, Z.S., Kwast, K.E., and Liu, J.S. 2004. Statistical resynchronization and Bayesian detection of periodically expressed genes. Nucleic Acids Res. 32: 447-455.

MacKay, V., Mai, B., Waters, L., and Breeden, L. 2001. Early cell cycle box-mediated transcription of CLN3 and SWI4 contributes to the proper timing of the G1-to-S transition in budding yeast. Mol. Cell. Biol. 21: 4140-4148.

Martinez-Pastor, M.T., Marchler, G., Schuller, C., MarchlerBauer, A., Ruis, H., and Estruch, F. 1996. The Saccharomyces cerevisiae zinc finger proteins Msn2p and Msn4p are required for transcriptional induction through the stress response element (STRE). EMBO J. 15: 2227-2235.

McInerny, C.J., Partridge, J.F., Mikesell, G.E., Creemer, D.P., and Breeden, L.L. 1997. A novel Mcm1-dependent element in the SWI4, CLN3, CDC6, and CDC47 promoters activates M/G1-specific transcription. Genes \& Dev. 11: 1277-1288.

McIntosh, E.M., Atkinson, T., Storms, R.K., and Smith, M. 1991. Characterization of a short, cis-acting DNA sequence which conveys cell cycle stage-dependent transcription in Saccharomyces cerevisiae. Mol. Cell. Biol. 11: 329-337.

Moses, A.M., Chiang, D.Y., Pollard, D.A., Iyer, V.N., and Eisen, M.B. 2004. MONKEY: Identifying conserved transcriptionfactor binding sites in multiple alignments using a binding site-specific evolutionary model. Genome Biol. 5: R98.

Nash, R., Tokiwa, G., Anand, S., Erickson, K., and Futcher, A.B. 1988. The WHI1 gene of Saccharomyces cerevisiae tethers cell division to cell size and is a cyclin homolog. EMBO J. 7: $4335-4346$.

Nourani, A., Wesolowski-Louvel, M., Delaveau, T., Jacq, C., and Delahodde, A. 1997. Multiple-drug-resistance phenomenon in the yeast Saccharomyces cerevisiae: Involvement of two hexose transporters. Mol. Cell. Biol. 17: 5453-5460.

Olsen, G.J., Matsuda, H., Hagstrom, R., and Overbeek, R. 1994. fastDNAmL: A tool for construction of phylogenetic trees of DNA sequences using maximum likelihood. Comput. Appl. Biosci. 10: 41-48.

Osley, M.A. and Lycan, D. 1987. Trans-acting regulatory mutations that alter transcription of $S$. cerevisiae histone genes. Mol. Cell. Biol. 7: 4204-4210.

Pearson, C.G., Yeh, E., Gardner, M., Odde, D., Salmon, E.D., and Bloom, K. 2004. Stable kinetochore-microtubule attachment constrains centromere positioning in metaphase. Curr. Biol. 14: 1962-1967. 
Pic, A., Lim, F.-L., Ross, S.J., Veal, E.A., Johnson, A.L., Sultan, M.R.A., West, A.G., Johnston, L.H., Sharrocks, A.D., and Morgan, B.A. 2000. The forkhead protein Fkh2 is a component of the yeast cell cycle transcription factor SFF. EMBO $J$. 19: $1-12$

Pramila, T., Miles, S., GuhaThakurta, D., Jemilo, D., and Breeden, L.L. 2002. Conserved homeodomain proteins interact with MADS box protein Mcml to restrict ECB-dependent transcription to the M/G1 phase of the cell cycle. Genes \& Dev. 16: 3034-3045.

Pringle, J.R. and Hartwell, L.H. 1981. The Saccharomyces cerevisiae cell cycle. In The molecular biology of the yeast Saccharomyces: Life cycle and inheritance (eds. J.N. Strathern et al.), pp. 97-142. Cold Spring Harbor Laboratories, Cold Spring Harbor, NY.

Sarin, S., Ross, K.E., Boucher, L., Green, Y., Tyers, M., and Cohen-Fix, O. 2004. Uncovering novel cell cycle players through the inactivation of securin in budding yeast. Genetics 168: 1763-1771.

Schmidt, M.C., McCartney, R.R., Zhang, X., Tillman, T.S., Solimeo, H., Wolfl, S., Almonte, C., and Watkins, S.C. 1999. Std1 and Mth1 proteins interact with the glucose sensors to control glucose-regulated gene expression in Saccharomyces cerevisiae. Mol. Cell. Biol. 19: 4561-4571.

Schroer, T.A. 2004. Dynactin. Annu. Rev. Cell Dev. Biol. 20: 759-779.

Sidorova, J.M. and Breeden, L.L. 2003. Precocious G1/S transitions and genomic instability: The origin connection. Mutat. Res. 532: 5-19.

Simon, I., Barnett, J., Hannett, N., Harbison, C.T., Rinaldi, N.J., Volkert, T.L., Wyrick, J.J., Zeitlinger, J., Gifford, D.K., Jaakkola, T.S., et al. 2001. Serial regulation of transcriptional regulators in the yeast cell cycle. Cell 106: 697-708.

Sinha, S., Blanchette, M., and Tompa, M. 2004. PhyME: A probabilistic algorithm for finding motifs in sets of orthologous sequences. BMC Bioinformatics 5: 170.

Spellman, P.T., Sherlock, G., Zhang, M.Q., Iyer, V.R., Anders, K., Eisen, M.B., Brown, P.O., Botstein, D., and Futcher, B. 1998. Comprehensive identification of cell cycle-regulated genes of the yeast Saccharomyces cerevisiae by microarray hybridization. Mol. Biol. Cell 9: 3273-3297.

Spencer, F., Gerring, S.L., Connelly, C., and Hieter, P. 1990. Mitotic chromosome transmission fidelity mutants in Saccharomyces cerevisiae. Genetics 124: 237-249.

Steinmetz, L.M., Scharfe, C., Deutschbauer, A.M., Mokranjac, D., Herman, Z.S., Jones, T., Chu, A.M., Giaever, G., Prokisch, H., Oefner, P.J., et al. 2002. Systematic screen for human disease genes in yeast. Nat. Genet. 31: 400-404.

Straight, A.F. and Murray, A.W. 1997. The spindle assembly checkpoint in budding yeast. Methods Enzymol. 283: 425440.

Stuart, D. and Wittenberg, C. 1996. CLN3, not positive feedback, determines the timing of CLN2 transcription in cycling cells. Genes \& Dev. 9: 2780-2794.

Sudarsanam, P., Pilpel, Y., and Church, G.M. 2002. Genomewide co-occurrence of promoter elements reveals a cis-regulatory cassette of rRNA transcription motifs in S. cerevisiae. Genome Res. 12: 1723-1731.

Tanaka, K., Mukae, N., Dewar, H., van Breugel, M., James, E.K., Prescott, A.R., Antony, C., and Tanaka, T.U. 2005. Molecular mechanisms of kinetochore capture by spindle microtubules. Nature 434: 987-994.

Tong, A.H., Lesage, G., Bader, G.D., Ding, H., Xu, H., Xin, X., Young, J., Berriz, G.F., Brost, R.L., Chang, M., et al. 2004. Global mapping of the yeast genetic interaction network. Science 303: 808-813.
Tyers, M., Tokiwa, G., and Futcher, B. 1993. Comparison of the Saccharomyces cerevisiae $\mathrm{G}_{1}$ cyclins: $\mathrm{Cln} 3$ may be an upstream activator of $C \ln 1, C \ln 2$ and other cyclins. EMBO $J$. 12: $1955-1968$.

Ubersax, J.A., Woodbury, E.L., Quang, P.N., Paraz, M., Blethrow, J.D., Shah, K., Shokat, K.M., and Morgan, D.O. 2003. Targets of the cyclin-dependent kinase Cdk1. Nature 425: 859-864.

Vodermaier, H.C. 2004. APC/C and SCF: Controlling each other and the cell cycle. Curr. Biol. 14: R787-R796.

Wang, X., Krupczak-Hollis, K., Tan, Y., Dennewitz, M.B., Adami, G.R., and Costa, R.H. 2002. Increased hepatic Forkhead Box M1B (FoxM1B) levels in old-aged mice stimulated liver regeneration through diminished $\mathrm{p} 27 \mathrm{Kip} 1$ protein levels and increased Cdc25B expression. J. Biol. Chem. 277: 44310-44316.

Whitfield, M.L., Sherlock, G., Saldanha, A.J., Murray, J.I., Ball, C.A., Alexander, K.E., Matese, J.C., Perou, C.M., Hurt, M.M., Brown, P.O., et al. 2002. Identification of genes periodically expressed in the human cell cycle and their expression in tumors. Mol. Biol. Cell 13: 1977-2000.

Winey, M. and O'Toole, E.T. 2001. The spindle cycle in budding yeast. Nat. Cell Biol. 3: E23-E27.

Wonsey, D.R. and Follettie, M.T. 2005. Loss of the forkhead transcription factor FoxM1 causes centrosome amplification and mitotic catastrophe. Cancer Res. 65: 5181-5189.

Yeh, E., Yang, C., Chin, E., Maddox, P., Salmon, E.D., Lew, D.J., and Bloom, K. 2000. Dynamic positioning of mitotic spindles in yeast: Role of microtubule motors and cortical determinants. Mol. Biol. Cell 11: 3949-3961.

Zhu, G. and Davis, T.N. 1998. The fork head transcription factor Hcmlp participates in the regulation of SPC110, which encodes the calmodulin-binding protein in the yeast spindle pole body. Biochim. Biophys. Acta 1448: 236-244.

Zhu, G., Muller, E.G., Amacher, S.L., Northrop, J.L., and Davis, T.N. 1993. A dosage-dependent suppressor of a temperaturesensitive calmodulin mutant encodes a protein related to the fork head family of DNA-binding proteins. Mol. Cell. Biol. 13: $1779-1787$

Zhu, G., Spellman, P.T., Volpe, T., Brown, P.O., Botstein, D., Davis, T.N., and Futcher, B. 2000. Two yeast forkhead genes regulated the cell cycle and pseudohyphal growth. Nature 406: 90-93. 


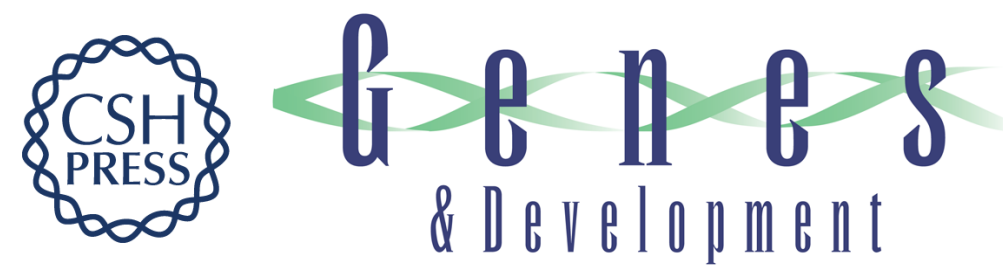

\section{The Forkhead transcription factor $\mathrm{Hcm} 1$ regulates chromosome segregation genes and fills the S-phase gap in the transcriptional circuitry of the cell cycle}

Tata Pramila, Wei Wu, Shawna Miles, et al.

Genes Dev. 2006, 20:

Access the most recent version at doi:10.1101/gad.1450606

Supplemental http://genesdev.cshlp.org/content/suppl/2006/08/02/20.16.2266.DC1

Material

References This article cites 80 articles, 36 of which can be accessed free at:

http://genesdev.cshlp.org/content/20/16/2266.full.html\#ref-list-1

License

Email Alerting Receive free email alerts when new articles cite this article - sign up in the box at the top

Service right corner of the article or click here.

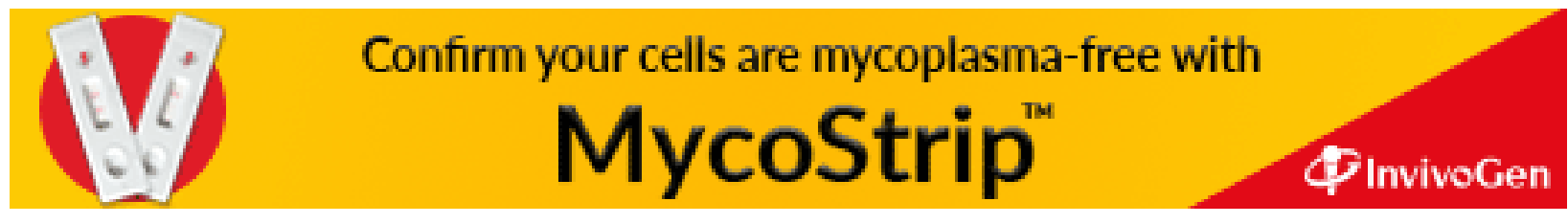

